Review

\title{
Vaccine-Associated Thrombocytopenia and Thrombosis: Venous Endotheliopathy Leading to Venous Combined Micro-Macrothrombosis
}

\author{
Jae C. Chang $1, *(1)$ and H. Bradford Hawley ${ }^{2}$ \\ 1 Department of Medicine, University of California Irvine School of Medicine, Irvine, CA 92868, USA \\ 2 Department of Medicine, Wright State University Boonshoft School of Medicine, Dayton, OH 45435, USA; \\ hbhawley@twc.com \\ * Correspondence: jaec@uci.edu; Tel.: +1-949-943-9988
}

Citation: Chang, J.C.; Hawley, H.B. Vaccine-Associated

Thrombocytopenia and Thrombosis: Venous Endotheliopathy Leading to Venous Combined

Micro-Macrothrombosis. Medicina 2021, 57, 1163. https://doi.org/

10.3390/medicina57111163

Academic Editor: Thomas Kühne

Received: 26 September 2021

Accepted: 19 October 2021

Published: 26 October 2021

Publisher's Note: MDPI stays neutral with regard to jurisdictional claims in published maps and institutional affiliations.

Copyright: (c) 2021 by the authors. Licensee MDPI, Basel, Switzerland. This article is an open access article distributed under the terms and conditions of the Creative Commons Attribution (CC BY) license (https:/ / creativecommons.org/licenses/by/ $4.0 /)$.

\begin{abstract}
Serious vaccine-associated side effects are very rare. Major complications of vaccines are thrombocytopenia and thrombosis in which pathogenetic mechanism is consistent with endotheliopathy characterized by "attenuated" sepsis-like syndrome, leading to the activation of inflammatory and microthrombotic pathway. In the COVID-19 pandemic, acute respiratory distress syndrome caused by microthrombosis has been the major clinical phenotype from the viral sepsis in association with endotheliopathy-associated vascular microthrombotic disease (EA-VMTD), sometimes presenting with thrombotic thrombocytopenic purpura (TTP)-like syndrome. Often, venous thromboembolism has coexisted due to additional vascular injury. In contrast, clinical phenotypes of vaccine complication have included "silent" immune thrombocytopenic purpura (ITP-like syndrome), multiorgan inflammatory syndrome, and deep venous thrombosis (DVT), cerebral venous sinus thrombosis (CVST) in particular. These findings are consistent with venous (v) EA-VMTD. In vEA-VMTD promoted by activated complement system following vaccination, "consumptive" thrombocytopenia develops as ITP-like syndrome due to activated unusually large von Willebrand factor (ULVWF) path of hemostasis via microthrombogenesis. Thus, the pathologic phenotype of ITP-like syndrome is venous microthrombosis. Myocarditis/pericarditis and other rare cases of inflammatory organ syndrome are promoted by inflammatory cytokines released from activated inflammatory pathway, leading to various organ endotheliitis. Vaccine-associated CVST is a form of venous combined "micro-macrothrombosis" composed of binary components of "microthrombi strings" from vEA-VMTD and "fibrin meshes" from vaccine-unrelated incidental vascular injury perhaps such as unreported head trauma. This mechanism is identified based on "two-path unifying theory" of in vivo hemostasis. Venous combined micro-macrothrombosis due to vaccine is much more serious thrombosis than isolated distal DVT made of macrothrombus. This paradigm changing novel concept of combined micro-macrothrombosis implies the need of combined therapy of a complement inhibitor and anticoagulant for CVST and other complex forms of DVT.
\end{abstract}

Keywords: combined micro-macrothrombosis; COVID 19 vaccines; endotheliopathy; immune thrombocytopenic purpura-like syndrome; multiorgan dysfunction syndrome; thrombotic thrombocytopenic purpura-like syndrome; venous endotheliopathy-associated vascular microthrombotic disease

\section{Introduction}

Although serious vaccine complications are rare, thrombocytopenia, cerebral venous sinus thrombosis (CVST), and inflammatory organ syndrome, such as myocarditis and pericarditis following COVID-19 vaccination, are well documented [1,2]. However, their pathogenetic mechanisms are poorly understood. In COVID-19 viral sepsis, acute respiratory distress syndrome (ARDS) is caused by complement-activated endotheliopathy leading to inflammation and vascular microthrombotic disease (VMTD) as previously analyzed [3]. Similar to vaccine, thrombocytopenia, deep vein thrombosis (DVT) and 
inflammation also have occurred in COVID-19 sepsis. The clinical features of ARDS, laboratory evidence of partial hemostasis, and pathologic phenotype of microthrombosis have been well-established to be caused by endotheliopathy triggering molecular pathogenesis $[3,4]$. Endotheliopathy promotes exocytosis of ULVWF multimers, which activates ULVWF path of hemostasis that leads to formation of microthrombosis and consumption of platelets leading to the thrombocytopenia. In addition, unexpected thrombosis oftentimes coexisted with microthrombosis presenting as macrothrombotic disease (i.e., venous thromboembolism (VTE)), which was likely caused by virus-unrelated additional vascular injury such as vascular access, device, procedure, surgery, or use of mechanical ventilation in hospital/ICU admitted patients [4]. This macrothrombotic disease has confounded clinicians in the understanding of its relationship to the underlying microthrombosis.

Thrombocytopenia and macrothrombotic disease of CVST after vaccination and those of VTE in COVID-19 sepsis are very similar in hemostatic features each other. Further, VTE also has occurred in vaccinated patients and CVST has developed in COVID-19 sepsis, and inflammation has been common finding in both. In view of similar clinical phenotypes of thrombosis, thrombocytopenia and inflammation occurring in both COVID-19 infection and vaccine complication, the pathogenesis of vaccine complication is suspected to be the result of a shared mechanism of endotheliopathy in sepsis. In this article, we will analyze the characteristic clinical and laboratory data in vaccine-induced hemostatic disease focusing on endothelial molecular pathogenesis utilizing "two activation theory of the endothelium".

\section{Endotheliopathy}

Complement activation initiated by a pathogen leads to endotheliopathy of the host that causes a hemostatic disease promoted by microthrombogenesis, leading to damage to the endothelial cells (ECs) [3,5]. Endotheliopathy activates two simultaneous but independent pathogenetic processes: inflammatory pathway and microthrombotic pathway. Each pathway promotes separate characteristic molecular pathogenesis. The former releases inflammatory cytokines such as interleukin 6, tumor necrosis factors, and interferons, and the latter promotes exocytosis of unusually large von Willebrand factor (ULVWF) multimers that initiate lone activation of ULVWF path of hemostasis [5]. Thus, sepsis is commonly manifested by inflammation, and endotheliopathy-associated VMTD (EA-VMTD) expressed as disseminated microthrombosis, which orchestrates thrombotic thrombocytopenic purpura (TTP)-like syndrome with the triad of consumptive thrombocytopenia, microangiopathic hemolytic anemia (MAHA) and hypoxic multiorgan dysfunction syndrome (MODS) [6].

Inactivated or killed pathogen vaccines, their subunits, or toxoid vaccines have long been theorized to promote pathogen-specific protective antibody production and $\mathrm{T}$ cell immune response against each specific pathogen [7], but also were sometimes associated with undesired vaccine-associated enhancement of viral infections [8] or "attenuated" sepsis-like syndrome. Indeed, the clinical features of thrombocytopenia, thrombosis, and inflammatory organ syndrome after COVID-19 vaccination have been similar to that of COVID-19 sepsis which causes inflammation and VMTD [9-11]. COVID-19 typically presents with endotheliopathy with microvascular microthrombosis in the lungs, causing ARDS, and occasionally thrombocytopenia, MAHA, and other organ syndromes, which have been called TTP-like syndrome $[3,4]$. However, vaccine-associated endotheliopathy does not cause TTP-like syndrome, but instead is manifested as "silent" immune thrombocytopenic purpura (ITP) [12,13], which can be called ITP-like syndrome. In addition, CVST [14,15] and multiorgan inflammatory syndrome (MOIS) $[16,17]$ have occurred after vaccination. The distinguishing clinical features of endotheliopathy-associated VMTD (EA-VMTD) between viral sepsis and vaccine complication can be explained by vascular physiologic, hemodynamic and histological differences of the vascular wall between the arterial system and venous system (Table 1), which include oxygen delivery function, pressure difference, shear stress, and vascular and microvascular networks. COVID-19 sepsis is consistent with combined venous and arterial endotheliopathy (i.e., venous EA-VMTD [vEA-VMTD] and 
arterial EA-VMTD [aEA-VMTD]) and the vaccine complication is exclusively congruous with the effect of venous endotheliopathy (i.e., vEA-VMTD).

Table 1. Clinical phenotypes and mechanisms of endotheliopathy in arterial and venous systems per "two-activation theory of the endothelium".

\begin{tabular}{|c|c|c|}
\hline Clinical Phenotype & Arterial Endotheliopathy & Venous Endothelipathy \\
\hline \multirow{5}{*}{$\begin{array}{l}\text { Underlying pathology } \\
\text { Physiological/hemodynamic } \\
\text { differences in the } \\
\text { vascular network }\end{array}$} & aEA-VMTD & vEA-VMTD \\
\hline & $\begin{array}{l}\text { Efferent circulation from the heart (oxygenated } \\
\text { blood delivery to the organs) }\end{array}$ & $\begin{array}{l}\text { Afferent circulation into the heart } \\
\text { (deoxygenated blood delivery to } \\
\text { the lungs) }\end{array}$ \\
\hline & High pressure flow & Low pressure flow \\
\hline & High shear stress & Low shear stress \\
\hline & Capillary and arteriolar microvascular event & $\begin{array}{l}\text { Venous and pulmonary } \\
\text { microvascular event }\end{array}$ \\
\hline \multicolumn{3}{|l|}{ Primary cause and result } \\
\hline Vascular injury (ECs) & Sepsis-induced microvascular endotheliopathy & $\begin{array}{l}\text { Sepsis-induced venous endotheliopathy } \\
\text { Vaccine-induced venous endotheliopathy }\end{array}$ \\
\hline Vascular pathology site & $\begin{array}{l}\text { Disseminated aEA-VMTD at the } \\
\text { microvasculature }\end{array}$ & $\begin{array}{l}\text { Transient or "silent" vEA-VMTD at } \\
\text { venous system }\end{array}$ \\
\hline Activated hemostatic path & ULVWF path & ULVWF path \\
\hline Thrombosis component & Microthrombi strings & Microthrombi strings \\
\hline \multirow[t]{2}{*}{ Clinical phenotypes } & TTP-like syndrome & ITP-like syndrome \\
\hline & $\begin{array}{ll}\text { - } & \text { consumptive thrombocytopenia } \\
\text { - } & \text { MAHA } \\
\text { - } & \text { MODS/MOIS }\end{array}$ & $\begin{array}{ll}\text { - } & \text { consumptive thrombocytopenia } \\
\text { - } & \text { Absence of hemolysis } \\
\text { - } & \text { MOIS }\end{array}$ \\
\hline
\end{tabular}

Abbreviations: aEA-VMTD, arterial endotheliopathy-associated vascular microthrombotic disease; vEA-VMTD, venous-VMTD; ECs, endothelial cells; ITP, immune thrombocytopenic purpura; MAHA, microangiopathic hemolytic anemia; MODS, multiorgan dysfunction syndrome; MOIS, multiorgan inflammatory syndrome; TTP, thrombotic thrombocytopenic purpura; ULVWF, unusually large von Willebrand factor.

The clinical features of the serious complication of COVID-19 vaccines are consistent with "venous endotheliopathy" leading to vEA-VMTD, which is characterized by ITP-like syndrome, inflammatory organ syndrome, and a complex form of DVT. In contrast, COVID19 sepsis, in addition to venous endotheliopathy, may also present with clinical features of "arterial endotheliopathy" leading to aEA-VMTD, which has been demonstrated by TTPlike syndrome, hypoxic MODS and arterial thrombosis/gangrene syndrome such as limb gangrene and symmetrical peripheral gangrene [4]. COVID-19 sepsis also has been associated with complex forms of DVT, such as VTE, pulmonary thromboembolism (PTE), and splanchnic vein thrombosis (SVT). These coexisting venous thrombotic syndromes and arterial endotheliopathy are consistent with the concept that COVID-19 sepsis promotes both aEA-VMTD and vEA-VMTD. The pathogenesis of complex forms of COVID-19-associated arterial and venous thrombotic syndromes has been identified by applying the "two-path unifying theory" of hemostasis on the formation of combined micro-macrothrombi [4]. This extraordinary mechanism will be elaborated later. Table 1 shows why vaccine complications are consistent with venous endotheliopathy (vEA-VMTD).

\section{Thrombocytopenia}

Thrombocytopenia is a very common complication in sepsis and other critically ill patients. As shown in novel "two-path unifying theory" of hemostasis (Figure 1), it occurs due to platelet consumption as a consequence of microthrombogenesis. Microthrombi are produced via endothelial molecular pathogenesis following activation of ULVWF path of hemostasis [5]. The "microthrombi strings" are composed of platelet-ULVWF complexes anchored to the endothelial membrane. It occurs in the capillaries and arterioles in aEAVMTD and perhaps in smaller veins in vEA-VMTD. In the past, when the mechanism of consumptive thrombocytopenia was not recognized, it had been called "thrombocytopenia in critically ill patients" (TCIP) [18]. 


\section{Normal in vivo hemostasis based on "two-path unifying theory"}

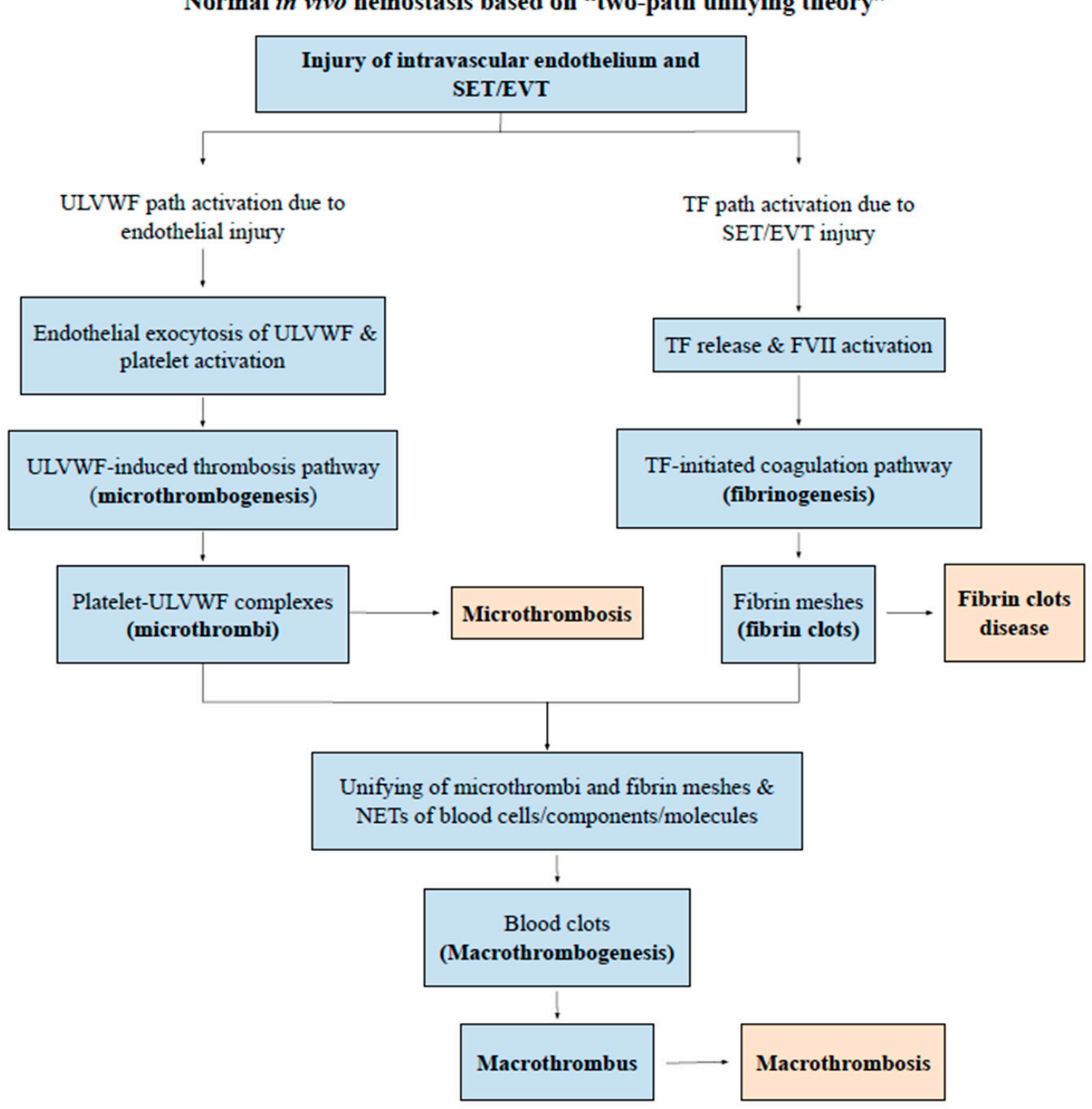

Figure 1. Normal in vivo hemostasis based on "two-path unifying theory" (Reproduced and modified with permission from Chang JC. Thrombosis Journal. 2019;17:10). Legends/Captions: Following a vascular injury, in vivo hemostatic system activates two independent sub-hemostatic paths: microthrombotic (ULVWF) and fibrinogenetic (TF). They are initiated by the damage of ECs and/or SET/EVT in a external bodily injury and intravascular injury. In the activated ULVWF path from ECs damage, ULVWF multimers are released and recruit platelets, and produce microthrombi strings via microthrombogenesis, but in the activated TF path from SET/EVT damage, released TF activates FVII and produces fibrin meshes via extrinsic coagulation cascade. The final path of in vivo hemostasis is macrothrombogenesis, in which microthrombi strings and fibrin meshes become unified together with incorporation of NETs, including red blood cells, neutrophils, DNAs and histones. This unifying event macrothrombogenesis promotes hemostatic plug formation and wound healing in external bodily injury and produces macrothrombosis in intravascular injury. Abbreviations: EA-VMTD, endotheliopathy-associated vascular microthrombotic disease: EVT, extravascular tissue; NETs, neutrophil extracellular traps; SET, subendothelial tissue; TF, tissue factor; ULVWF, unusually large von Willebrand factor.

Since both sepsis and vaccination are associated with aEA-VMTD and/or vEAVMTD, thrombocytopenia following vaccination is obviously due to consumption from microthrombogenesis. To date, the pathogenesis of ITP, both idiopathic type and immunedesignated type, has been considered to be due to immune destructive mechanism of platelets [19-22]. In the COVID-19 pandemic, thrombocytopenia occurring in vaccineassociated thrombosis has been called "COVID-19 vaccine-associated (immune) thrombosis 
and thrombocytopenia (VITT)" $[1,23,24]$, often related to platelet factor 4 (PF4) antibodies $[25,26]$. However, no clear cause-effect relationship has been established [27] between thrombocytopenia and macrothrombosis, as well as thrombocytopenia and anti-PF4 antibodies. Indeed, the mechanism of thrombocytopenia, either platelet consumption or destruction in vaccine-associated thrombocytopenia and thrombosis, has not been determined. The concept of ITP cannot be defined properly without comprehension of "endothelial molecular pathogenesis". Figure 2 illustrates the pathogenesis of endotheliopathy based on "two-activation theory of the endothelium" [18], and the "two-path unifying theory" of hemostasis is shown in Figure 1 [28]. Based on these theories, we have also formulated the pathogenesis of vaccine-associated endotheliopathy", as illustrated in Figure 3.

\section{Endotheliopathy based on "two-activation theory of the endothelium"}

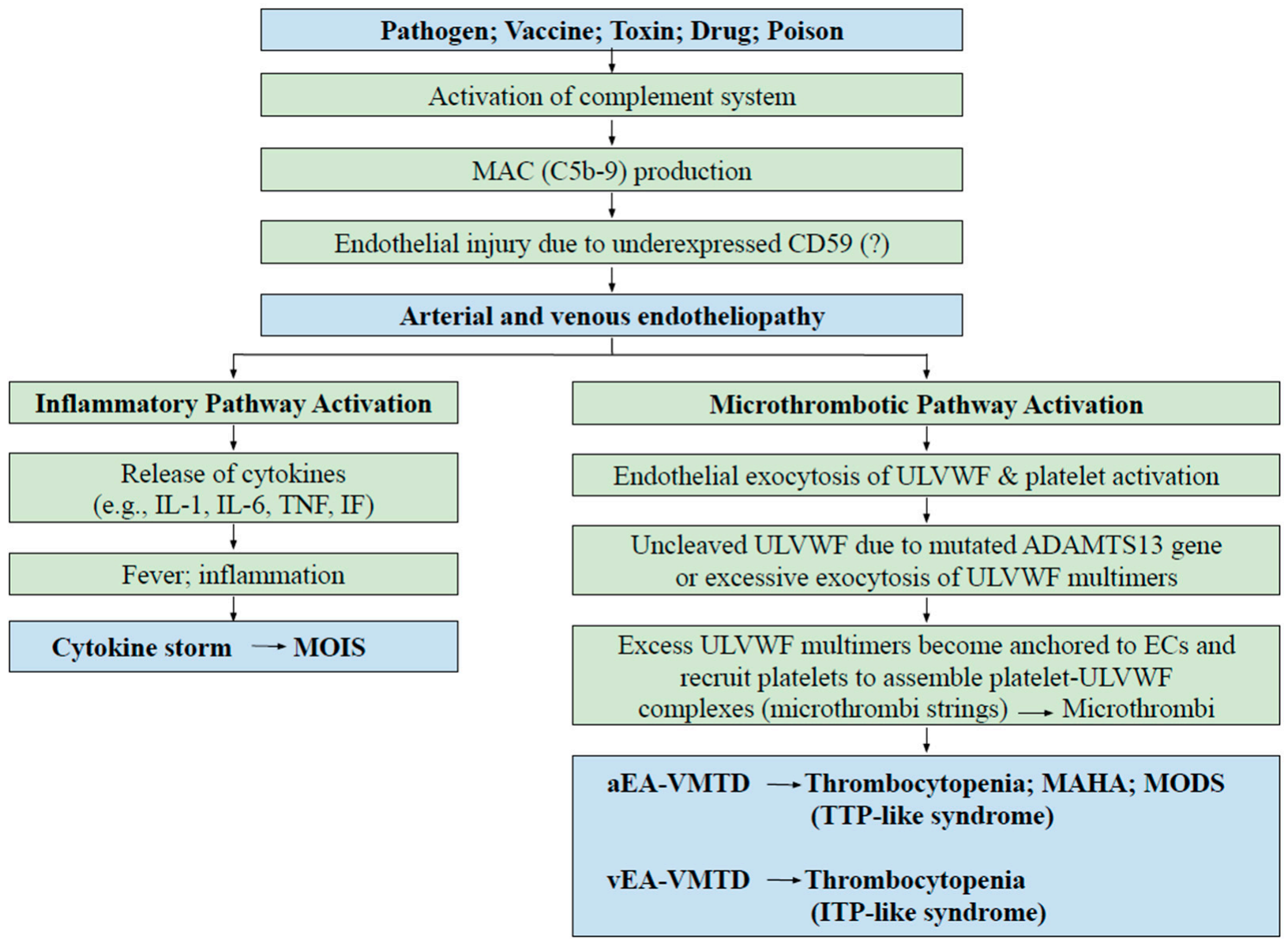

Figure 2. Endotheliopathy based on "two-activation theory of the endothelium". Endothelial molecular pathogenesis is initiated by activation of complement system triggered from pathogen, vaccine, toxin, drug, poison, or others. However, unlike pathogen-induced sepsis, vaccine-induced clinical syndrome is almost always due to venous endotheliopathy because it has produced ITP-like syndrome rather than TTP-like syndrome occurring in arterial endotheliopathy as explained in the text. These distinguishing features are caused by differences in physiological function and hemodynamic characteristics between the arterial system and venous system. Therefore, MAHA and hypoxic MODS do not occur in vaccine-associated endotheliopathy. However, inflammatory syndromes (MOIS) such as myocarditis and pericarditis could occur after vaccination instead of hypoxic MODS. Abbreviations: ITP, immune thrombocytopenic purpura; MAC, membrane attack complex; IF, interferon; IL, interleukin; MAHA, microangiopathic hemolytic anemia; MODS, multiorgan dysfunction syndrome; MOIS, multiorgan inflammatory syndrome; TNF, tumor necrosis factor; TTP, thrombotic thrombocytopenic purpura; aEA-VMTD, arterial endotheliopathy-associated vascular microthrombotic disease; vEA-VMTD, venous endotheliopathy-associated vascular microthrombotic disease; ULVWF, unusually large von Willebrand factor multimers. 


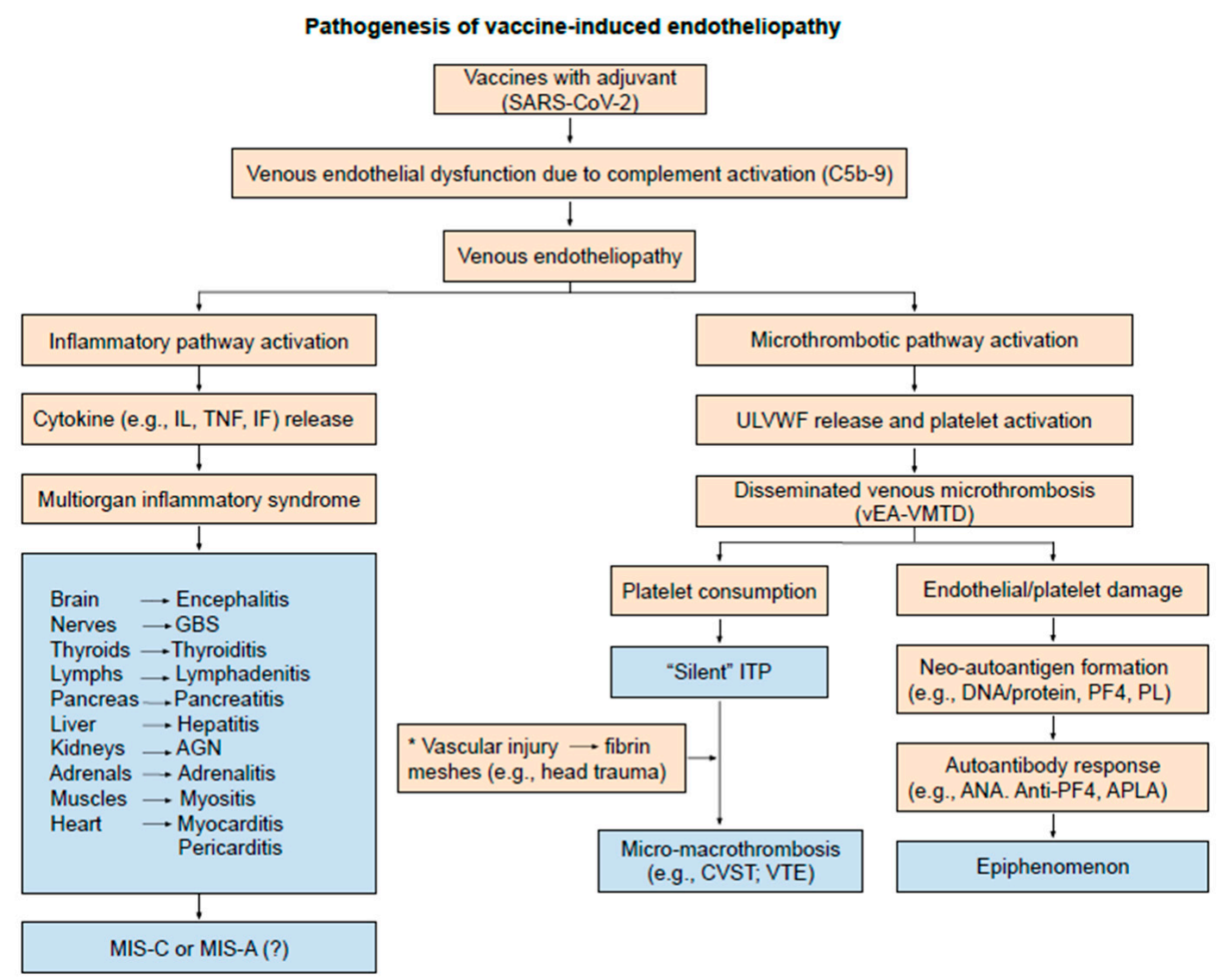

Figure 3. Pathogenesis of vaccine-induced endotheliopathy. The venous endothelial pathogenesis in SARS-CoV-2 vaccines is self-explanatory. Compared to aEA-VMTD/vEA-VMTD of sepsis, vEA-VMTD from vaccination does not typically cause MAHA and life-threatening hypoxic MODS. However, it can cause its share of another combined micro-macrothrombotic syndrome, a complex form of DVT, especially CVST as explained in the text. Incidentally, the occurrence of VTE in sepsis and CVST in vaccination provides additional insights in thrombogenesis for the important role of vascular accesses in the hospitalized patient, ICU in particular. Sub-references for observed MOIS shown in Table S1 are available in Supplementary file. Abbreviations: aEA-VMTD, arterial endotheliopathy-associated VMTD; vEA-VMTD, venous EA-VMTD; APLA, antiphospholipid antibodies; PF4, platelet factor 4; PL, phospholipids; CVST, cerebral venous sinus thrombosis; DVT, deep venous thrombosis; ITP, immune thrombocytopenic purpura; MAHA, microangiopathic hemolytic anemia; MIS-C, multisystem inflammatory syndrome in children; MIS-A, MIS in adults; MODS, multiorgan dysfunction syndrome; MOIS, multiorgan inflammatory syndrome; VTE, venous thromboembolism; AGN, acute glomerulonephritis; GBS, Guillain-Barre syndrome: IF, interferon, IL, interleukin; TNF, tumor necrosis factor.

The pathogenesis presented in Figure 3 is logical and straightforward. Vaccineassociated venous endotheliopathy activates two pathogenetic pathways. One is the inflammatory pathway promoting MOIS such as myocarditis, pericarditis, thyroiditis [29,30], lymphadenitis [31,32] and others as exampled in Table S1, and the other is the microthrombotic pathway promoting ITP-like syndrome of microthrombosis in the venous system. ITP-like syndrome may be "calm before storm" because it can be transformed itself into deadly combined micro-macrothrombosis (e.g., CVST) if complicated by additional vascular injury (e.g., incidental head injury following vaccination) as pointed in Figure 3.

Perhaps, following mild venous endotheliopathy after vaccination, most of microthrombi strings could rapidly undergo physiologic microthrombolysis by protease ADAMTS13, which results in the breakdown of platelets, as well as ECs and ULVWF multimers. This microthrombolysis can lead to release of platelet antigens such as PF4, phospholipids (PL), and other proteins which may become neo-autoantigen and produce anti-PF4 antibodies $[25,26]$ and anti-PL antibodies [33]. There is no proof that thrombocytopenia is the 
result of platelet destruction due to anti-PF4 antibodies or anti-PL antibodies. Furthermore, solitary thrombosis (e.g., distal DVT) formation is a local or regional hemostatic process and requires only small amounts of platelets without consequence of thrombocytopenia. On the contrary, thrombocytopenia in TTP-like syndrome, ITP-like syndrome, and TCIP in bacterial and viral sepsis is not of immunologic mechanism, but due to consumption of platelets in the process of microthrombogenesis triggered by generalized endotheliopathy [18].

Thus, in the early phase of viral sepsis and vaccination, positive anti-PF4 antibodies and anti-PL antibodies as well as antinuclear antibodies, and anti-dsDNA antibodies observed in endotheliopathy are likely an "epiphenomenon" unrelated to thrombosis $[27,34,35]$. Additionally, most cases of chronic and acute ITP are suspected to be the phenotypes of vEA-VMTD, which also explains the paradox of thrombophilic state producing complex forms of DVT in patients with ITP. This mystery has been articulated by many concerned hematologists [36-38]. The intriguing relationship between vEA-VMTD (i.e., ITP-like syndrome) and thrombophilic state of macrothrombosis (i.e., DVT) will be addressed in the heading of the "pathogenesis of venous combined micro-macrothrombotic syndromes" derived from the unifying mechanism of hemostasis [28].

\section{Thrombosis}

The term "thrombosis" has been used to denote every "blood clot(s)" in circulation as a generic disease entity in both arterial and venous systems. According to contemporary dogma, "thrombosis" in vivo is produced via extrinsic cascade progression from TF release out of subendothelial tissue (SET) to activation of coagulation factors, involving various serine proteases, protein substrates and fibrinogen, and to formation of fibrin meshes/fibrin $\operatorname{clot}(\mathrm{s})$. However, this simple concept of thrombogenesis based on TF activating extrinsic coagulation system alone cannot define the clinical and pathological aspects of many different thrombotic disorders observed in clinical medicine and pathology. Examples are:

- Macrothrombosis includes DVT, VTE, CVST, PTE, splanchnic vein thrombosis (SVT) and Budd-Chiari syndrome, portal vein thrombosis, acute ischemic stroke, acute myocardial infarction, aortic thrombus and renal vein thrombosis, etc.

- Microthrombosis (i.e., VMTD) occurs in TTP, TTP-like syndrome, ARDS, diffuse encephalopathic stroke, microvascular myocardial infarction, hemolytic-uremic syndrome, transient ischemic attack, microaneurysm and thrombosis of retinal artery, MODS, and hepatic veno-occlusive disease.

- Heparin-induced thrombocytopenia with thrombosis syndrome, especially white clot syndrome, is a unique aberrant hemostatic disease without vascular injury.

- Gangrene syndrome associated with arterial combined micro-macrothrombosis includes symmetrical peripheral gangrene (SPG), purpura fulminans, Fournier's gangrene in acute promyelocytic leukemia (APL), Burger's disease, diabetic gangrene, Raynaud's phenomenon, and acute necrotizing fasciitis.

- Fibrin clot disease occurs in APL as aberrant hemostatic disease without vascular injury.

- Acute "disseminated intravascular coagulation (DIC)" is a form of VMTD with hemorrhagic complication.

- Concurrent microthrombosis and macrothrombosis in both arterial and venous systems in paroxysmal nocturnal hemoglobinuria $(\mathrm{PNH})$ is an unresolved disease yet.

Certainly, many different forms of thrombosis do occur resulting from complexity of hemostatic mechanism affected by: (1) two sub-hemostatic paths (i.e., ULVWF and/or TF); (2) their unifying path to macrothrombogenesis; (3) venous or arterial systems; (4) microvasculature or larger vasculature; (5) localization in different vascular trees (i.e., localized and generalized, and solitary and multiple); and (6) altered hemostatic components associated with mutated genes (e.g., protein C, protein S, FV Leiden, and ADAMTS13, etc.). These variable combinations produce different forms of thrombi which vary in the size, number, tissue and organ location, and vascular system affected and determine many different clinical phenotypes [39,40]. Therefore, the inclusively designated term "thrombosis" can- 
not provide clinically explicative diagnosis for each thrombotic disorder because the term thrombosis only means an "existential" blood clotting disorder [39,41].

For example, although distal DVT and proximal/central(catheter) DVT are recognized as the same character disease of macrothrombus in the venous system, these two disorders are suspected to be caused by very different molecular composites expressing as two dissimilar clinical, pathological and radiological phenotypes (Table 2). Likewise, the pathologic phenotypes of acute ischemic stroke in the arterial system and CVST in the venous sinus occur as the result of macrothrombus, but their clinical phenotypes are different not only because of their location in the brain and blood vessel but also because of their character of the blood clot. On the other hand, the clinical phenotype of CVST stroke may be very similar to diffuse encephalopathic stroke, their pathologic phenotypes are distinctly different because the former is due to localized venous macrothrombosis, but the latter is due to disseminated microvascular microthrombosis [40].

Table 2. Two faces of deep venous thrombosis with pathologic, pathogenetic and laboratory differences based on two-path unifying theory of hemostasis and endothelial molecular pathogenesis.

\begin{tabular}{|c|c|c|}
\hline Phenotypes & $\begin{array}{l}\text { Distal DVT (de novo Venous } \\
\text { Macrothrombosis) }\end{array}$ & $\begin{array}{l}\text { Proximal/Central DVT (Combined Venous } \\
\text { Micro-Macro thrombosis) }\end{array}$ \\
\hline \multicolumn{3}{|l|}{ Disease examples } \\
\hline \multicolumn{3}{|l|}{ Venous thrombosis } \\
\hline DVT & Distal DVT & Proximal/central(catheter) DVT \\
\hline VTE & & VTE; multiple PTE \\
\hline Other complex venous thrombosis & & IVCT; SVT; PVT; BCS; SVCT; CVST \\
\hline \multicolumn{3}{|l|}{ Mechanisms of vascular injury } \\
\hline Event & $\begin{array}{l}\text { Local trauma (rarely with } \\
\text { surgery/vascular access) }\end{array}$ & $\begin{array}{l}\text { Underlying disease (vEA-VMTD (e.g., sepsis)) + local } \\
\text { trauma (commonly with surgery/vascular access) }\end{array}$ \\
\hline Extent of vascular damage & Local ECs/SET injury & $\begin{array}{l}\text { Disseminated ECs injury + local/regional } \\
\text { ECs/SET injury }\end{array}$ \\
\hline \multicolumn{3}{|l|}{ Pathogenesis } \\
\hline Activated thrombosis path & ULVWF and TF paths from local trauma & $\begin{array}{l}\text { ULVWF path from systemic vEA-VMTD and TF } \\
\text { path from regional trauma }\end{array}$ \\
\hline Thrombi character & Macrothrombus & $\begin{array}{l}\text { Combined micro-macrothrombi composed of } \\
\text { "microthrombi strings-fibrin meshes" }\end{array}$ \\
\hline Severity & Typically, solitary, benign, and self-limited & Serious and often with multiple/large thrombi \\
\hline Severe inflammation & Absent & May be present and can be severe \\
\hline Venous EA-VMTD & Absent & Commonly present (e.g., ITP-like syndrome) \\
\hline MOIS & Absent & May be present \\
\hline \multicolumn{3}{|l|}{ Diagnostic findings/markers } \\
\hline Consumptive thrombocytopenia & Does not occur & Sometimes occurs \\
\hline ULVWF/VWF antigen & Normal & Overexpressed \\
\hline FVIII activity & Normal & Increased \\
\hline ADAMTS13 activity & Normal & Mild to moderately decreased \\
\hline D-dimer & Normal & Markedly increased \\
\hline $\begin{array}{l}\text { Immune: ANA; APLA; } \\
\text { Anti-DNA antibodies }\end{array}$ & Negative & May be positive \\
\hline Therapeutic approach per theory & No treatment or short-term anticoagulant & $\begin{array}{l}\text { Anticoagulant and } \\
\text { antimicrothrombotic/anticomplement agent (?) }\end{array}$ \\
\hline
\end{tabular}

Abbreviations: ANA, antinuclear antibodies; APLA, antiphospholipid antibodies; BCS, Budd-Chiari syndrome; CVST, cerebral venous sinus thrombosis; DNA, deoxyribonucleic acid; DVT, deep vein thrombosis; vEA-VMTD, venous endotheliopathy-associated vascular microthrombotic disease; ECs, endothelial cells; EVT, extravascular tissue; ITP, immune thrombocytopenic purpura; IVCT, inferior vena cava thrombosis, MOIS, multiorgan inflammatory syndrome; PTE, pulmonary thromboembolism; PVT, portal vein thrombosis; SET, subenthelial tissue; SVCT, superior vena cava thrombosis; SVT, splanchnic vein thrombosis; TF, tissue factor; ULVWF, unusually large von Willebrand factor; vEA-VMTD, venous endotheliopathy-associated vascular microthrombotic diseases; VTE, venous thromboembolism; VWF, Von Willebrand factor.

\section{Cerebral Venous Sinus Thrombosis}

Now, how did CVST, which is a form of DVT, develop as macrothrombosis in both sepsis due to a pathogen and vaccine as a side effect?

There are two different pathogenetic phenotypes of DVT. One is from trauma resulting in local injury that causes localized solitary/distal DVT composed of fibrin clot (macrothrombosis). The other is vascular injury-induced DVT in a hospitalized patient with sepsis or coexisting underlying disease or conditions, such as diabetes, hypertension, atherosclerosis, pregnancy and cancer, or in a vaccinated individual with ITP-like 
syndrome (e.g., vEA-VMTD). In the latter situations, microthrombosis might have already existed, but was further complicated by additional localized vascular damage provoking micro-macrothrombosis. These underlying microthrombi and newly formed fibrin meshes can unify together in circulation and produce a localized or regional DVT complex (i.e., proximal/central DVT) producing combined micro-macrothrombosis characterized by multiple, large, extended, irregular and connected or disconnected binary micro-macrothrombi complexes. Distal DVT is a benign disease, but proximal/central DVT is a life-threatening malignant disease. The pathogenetic mechanism of CVST occurring in sepsis or following vaccination is promoted by the same mechanism of unifying process of micro-macrothrombogensesis, but in vaccinated individuals it is more likely occurring in the outpatient setting. In those individuals, CVST could have been due to unreported incidental head injury [42], which is a not uncommon trauma in life.

CVST has been very rare in both COVID-19 infection and post-vaccination, but it is seen more commonly than other DVT among the non-hospitalized vaccinated individuals. On the other hand, VTE and other DVT have more commonly occurred than CVST among hospitalized COVID-19 infected patients, in which cases vascular access injury such as surgery could have played a major role. Therefore, exclusive occurrence of CVST following outpatient vaccination might have been related to unidentified head injury. Indeed, following COVID-19 vaccines severe headache was present with thrombocytopenia prior to the diagnosis of CVST in some patients [43], which suggests unreported incidental head trauma might have preceded CVST and underlying ITP-like syndrome might have preexisted. To understand the mystery of combined micro-macrothrombosis manifesting as a phenotype of complex DVT as well as CVST, the two basic concepts of hemostasis should be applied; one is the mechanism of preexisting microthrombogenesis (i.e., underlying venous endotheliopathy), and the other is the "unifying mechanism" of "microthrombi" from vEA-VMTD and "fibrin meshes" from local vascular injury as follows.

\section{Pathogenesis of Venous Combined Micro-macrothrombotic Syndromes}

The normal unifying mechanism between microthrombi strings and fibrin meshes following a local vascular injury (e.g., aortic aneurysm with intraluminal thrombosis and distal DVT) is a localized natural process of hemostasis as shown in Figure 1 [28,39]. However, the same unifying process of "microthrombi strings" from septic/vaccine endotheliopathy and "fibrin meshes" from vascular injury in or outside of the hospital, leading to combined micro-macrothrombosis, seems to be a far-fetched proposition. However, its pathogenetic mechanism logically explains clinical and laboratory findings of each of the arterial and venous combined micro-macrothrombotic syndromes [4,5], as detailed in Tables 3 and 4. Arterial combined micro-macrothrombosis leads to gangrene syndromes (e.g., SPG), but venous micro-macrothrombotic syndrome leads to complex DVT (e.g., VTE). These phenotypes display striking clinical/radiological imaging features with poor prognostic outcome and raise serious issues in clinical management.

In the venous system, prior to vascular injury vEA-VMTD (i.e., "silent" ITP/ITP-like syndrome) could have already existed due to an underlying disease, such as diabetes or hypertension, or COVID-19 vaccines could have initiated venous endotheliopathy leading to "silent" microthrombosis. This ITP-like syndrome can be transformed to venous combined micro-macrothrombosis such as CVST when fibrin meshes are released into cerebral venous sinus circulation due to head trauma even in an outpatient setting, as noted in Figure 3. The results of the unified micro-macrothrombi in venous sinuses of the vaccinated individuals would be less dramatic in clinical phenotype than that of gangrene type in arterial circulation because of two reasons in the venous system; first, blood circulation is afferent toward the heart so that combined micro-macrothrombi present in blood returning to the heart do not cause tissue and organ hypoxia/anoxia; second, because the unifying process of "fibrin meshes" and "microthrombi strings" is slow and continuous with low shear stress flow, it does not produce minute macrothrombi, but forms large, multiple, irregular, extended. and connected or disconnected striped 
blood clots made of micro-macrothrombi complexes at vicinity of the venous injury. This mechanism produces complex forms of DVT in different locations (e.g., VTE, PTE, SVT, CVST, PVT, BCS, etc). Although the binary character of the micro-macrothrombi complex is the same to that of arterial circulation, different physiologic and hemodynamic nature between arterial and venous systems assembles completely different clinical phenotypes of "micro-macrothrombi" listed in Table 3. Summarized in Table 4 is a diagnostic guide for vaccine-associated vEA-VMTD and it also identifies major clinical components in differential diagnosis from sepsis-associated aEA-VMTD.

Table 3. Spectrum of combined micro-macrothrombotic syndromes.

\begin{tabular}{l} 
Pathology/Phenotypes \\
\hline Primary pathogenesis \\
Cause example \\
\\
Activated hemostatic path \\
Involved vessels \\
Underlying thrombophlia \\
Endothelial pathogenesis \\
Phenotype and marker \\
Thrombosis character \\
Clinical phenotype
\end{tabular}

Endothelial markers Secondary pathogenesis Cause of additional vascular injury

Activated hemostatic path Affected vessels Molecular phenotype

Pathologic phenotype

\author{
Clinical syndrome \\ Examples of syndromes
}

$\begin{array}{ll}\begin{array}{l}\text { Arterial Micro-Macrothrombotic Syndrome } \\ \text { (aEA-VMTD) }\end{array} & \begin{array}{l}\text { Venous Micro-Macrothrombotic Syndrome } \\ \text { (vEA-VMTD) }\end{array}\end{array}$

Pathogen-associated endotheliopathy (SARS-CoV-2)

\author{
ULVWF path via damaged ECs \\ Capillaries/arterioles \\ ADAMTS13 insufficiency \\ Complement activation
}

Arterial microvascular microthrombi

TTP-like syndrome

Consumptive thrombocytopenia

MAHA

MODS/MOIS

ULVWF ( $\uparrow$ VWF antigen $\uparrow$ FVIII activity)

From arterial vascular access in hospital

From arterial vascular injury outside hospital

TF path via damaged SET

Terminal arterial trees

Microthrombi and fibrin meshes

Numerous, minute macrothrombi shower composed of microthrombi and fibrin meshes in arterioles and capillaries in the digits, producing well-demarcated peripheral gangrene

Arterial micro-macrothrombosis

(Gangrene syndrome)

SPG, PF, ANF, diabetic gangrene, limb

gangrene, Fournier's disease, Burger's disease,
Pathogen-induced endotheliopathy

(SARS-CoV-2)

Vaccine-associated endotheliopathy

(SARS-CoV-2 vaccines)

ULVWF path via damaged ECs

Veins/venules

ADAMTS13 insufficiency(?)

Complement activation

Venous microthrombi

ITP-like syndrome ("Silent" ITP)

Consumptive thrombocytopenia MOIS

\section{ULVWF ( $\uparrow$ VWF antigen $\uparrow$ FVIII activity)}

From venous vascular access in hospital

From incidental head injury (?) after vaccine (e.g., CVST)

TF path via damaged SET

Localized veins at injury site

Microthrombi and fibrin meshes

Large, multiple, irregular, connected macrothrombi made of microthrombi and fibrin meshes in local or regional veins, producing DVT complex and venous stasis

Venous micro-macrothrombosis (complex DVT syndrome)

VTE, CVST, IVCT, PTE, BCS, PVT, SVCT, SVT acrocyanosis)

Abbreviations: aEA-VMTD, arterial endotheliopathy-associated vascular microthrombotic disease; vEA-VMTD, venous-VMTD; ANF, acute necrotizing fasciitis; BCS, Budd-Chiari syndrome; CVST, cerebral venous sinus thrombosis; ECs, endothelial cells, DVT, deep venous thrombosis; IVCT, inferior vena cava thrombosis; PF, purpura fulminans; PTE, pulmonary thromboembolism; PVT, portal vein thrombosis; SET, subendothelial issue; SPG, symmetrical peripheral gangrene; SVCT, superior vena cava thrombosis; SVT, splanchnic vein thrombosis; TF, tissue factor; PTE, pulmonary thromboembolism; ULVWF, unusually large von Willebrand factor: VTE, venous thromboembolism.

Fortunately, the vaccinated individual avoids the risk of in-hospital vascular injury, which is thought be the reason why, instead of VTE, CVST is more prevalent after vaccination, likely due to incidental head injury which may be the main risk factor in the outpatient setting. However, if a vaccinated CVST patient is admitted to the hospital, the risk for other complex forms of DVT is expected to rise due to inherent nature of vascular events in the hospital, and in the ICU in particular. 
Table 4. Diagnostic clinical and laboratory findings due to combined micro-macrothrombosis in aEA-VMTD and vEA-VMTD.

\begin{tabular}{ll}
\hline $\begin{array}{l}\text { Combined Micro-Macrothrombosis due to aEA-VMTD } \\
\text { (Gangrene Syndromes) (e.g., Sepsis) }\end{array}$ & $\begin{array}{c}\text { Combined Micro-Macrothrombosis due to vEA-VMTD } \\
\text { (Proximal/Central DVT) (e.g., Sepsis or after Vaccination) }\end{array}$ \\
\hline Clinical features & Clinical features \\
Fever/fatigue/myalgia & Fever/fatigue/myalgia \\
TTP-like syndrome with thrombocytopenia and MAHA & ITP-like syndrome (“Silent” ITP) \\
MODS (e.g., ARDS; encephalopathy) & MOIS (e.g., myocarditis; pericarditis) \\
Gangrene syndromes (e.g., SPG; limb gangrene) & VTE (e.g., VTE; CVST; PTE; SVT) \\
“Gangrene” & "Venous congestion syndrome” \\
Laboratory changes (demonstrated) & Laboratory changes (demonstrated or expected) \\
Endothelial (ULVWF path) markers & Endothelial (ULVWF path) markers \\
Consumptive thrombocytopenia & Consumptive thrombocytopenia \\
Overexpressed ULVWF/VWF antigen & Overexpressed ULVWF/VWF antigen \\
Increased FVIII activity & Increased FVIII activity \\
Increased thrombomodulin & Increased thrombomodulin \\
Endothelial epiphenomenon & Endothelial epiphenomenon \\
Positive ANA & Positive ANA \\
Positive anti-dsDNA & Positive anti-dsDNA \\
Positive anti-PL antibodies & Positive anti-PL antibodies \\
Positive PF4 antibodies & Positive PF4 antibodies \\
Tissue factor path markers & Tissue factor path markers \\
Positive D-dimer & Positive D-dimer \\
TF-bearing microvesicles in circulation & TF-bearing microvesicles in circulation (expected)
\end{tabular}

Abbreviation: ANA, antinuclear antibodies; CVST, cerebral venous sinus thrombosis; aEA-VMTD, arterial endotheliopathy-associated vascular micro-thrombotic disease; vEA-VMTD, venous EA-VMTD; MODS, multiorgan dysfunction syndrome; MOIS, multi-organ inflammatory syndrome; ITP, immune thrombocytopenic purpura; PF4, platelet factor 4; PL, phospholipids; PTE, pulmonary thromboembolism; SPG, symmetrical peripheral gangrene; SVT, splanchnic vein thrombosis; TTP, thrombotic thrombocytopenic purpura; VTE, venous thromboembolism.

\section{Molecular Evidence of Venous Endotheliopathy}

EA-VMTD resulting from the pathogenesis of COVID-19 sepsis-associated endotheliopathy can be manifested by clinical phenotypes of ARDS and MODS, pathologic phenotype of microthrombosis, and laboratory findings of TTP-like syndrome (i.e., consumptive thrombocytopenia and MAHA) in rare cases and ITP-like syndrome in many cases. Furthermore, EA-VMTD in COVID-19 sepsis has been characterized by elevated endothelial markers (i.e., increased activity of FVIII, and overexpressed ULVWF/VWF antigen), and decreased ADAMTS13 activity [4]. Thus, coexisting VTE and PTE can be inferred as combined micro-macrothrombosis resulting from underlying ITP-like syndrome of vEA-VMTD and virus-unrelated another vascular injury. These multiple clinical phenotypes are consistent with the proposition that COVID-sepsis causes both aEA-VMTD and vEA-VMTD. On the other hand, limited clinical features of vaccine-associated endotheliopathy to ITP-like syndrome and CVST are consistent with vEA-VMTD.

In the medical literature, CVST cases that occurred in pre-pandemic era were characterized by markedly overexpressed endothelial markers of VWF antigen and activity [44-47] and increased activity of FVIII [44,45,48-52], just as in COVID-19 sepsis-associated CVST. These findings certainly confirm that venous endotheliopathy existed as the underlying pathology of ITP-like syndrome prior to occurrence of post-vaccine CVST. These abnormal endothelial markers should be confirmed from every CVST patients with vaccine-associated thrombocytopenia.

Separately, as previously mentioned, thrombocytopenia in the vaccinated patients is due to consumption of platelets, and positive anti-PF4 antibodies and anti-PL antibodies as well as antinuclear antibody and anti-dsDNA antibody are more consistent with epiphenomenon of venous endotheliopathy unrelated to thrombocytopenia or thrombosis including CVST. The epiphenomenon was likely a secondary event following endothelial cell and platelet protein damage. This epiphenomenon is one of the lessons we have learned from COVID-19 sepsis [53]. In retrospect, some of the vaccinated individuals had 
ITP-like syndrome and CVST was formed as venous combined micro-macrothrombosis following additional cerebral venous sinus injury [54].

Complement activation plays the key role in vaccine-induced endotheliopathy, contributing to the endothelial molecular pathogenesis [55-58]. In addition, certain adjuvants and surfactants conjugated with vaccines trigger complement activation and causes injury to the endothelium, especially if an individual is mild to moderately deficient in ADAMTS13, which may promote venous endotheliopathy. In both COVID-19 sepsis and vaccination, the ligand spike (S) protein from SARS-CoV-2 has been thought to interact with the ACE2 receptor on the endothelial cells (ECs) of the host and activate complement system [59] and produce C5b-9 complex, which can lead to endotheliopathy. It promotes both inflammation and microthrombogenesis by releasing inflammatory cytokines and ULVWF multimers $[16,60]$, as seen in sepsis. The adjuvants and surfactants polyethylene glycol and polysorbate 80 , and graphene oxide sometimes used in vaccines are known to trigger complement activation [61-63]. These chemicals turn on the complement when they are attached to molecules, especially lipids. The size of the adenovirus delivered lipid coated particle is larger than the mRNA lipid coated particle, which may more likely lead to complement activation [64].

\section{Diagnostic and Therapeutic Consideration}

\subsection{Diagnostic Perspective}

The earliest indicator suggestive of venous endotheliopathy following vaccination is asymptomatic thrombocytopenia (ITP-like syndrome). CVST or DVT presenting with obvious macrothrombosis and persistent inflammation should alert the possibility of serious complication of vaccination. The diagnosis of venous combined micro-macrothrombosis can be established with the laboratory findings of (1) thrombocytopenia; (2) overexpressed ULVWF/VWF antigen or activity; (3) increased activity of FVIII; (4) markedly increased D-dimers; and (5) increased thrombomodulin [65], as shown in Table 4. Thrombocytopenia is the result of platelet consumption and is not due to immune destruction. Overexpressed ULVWF/VWF antigen, increased activity of FVIII and thrombomodulin in CVST are endothelial markers released from endotheliopathy, support on-going microthrombogenesis resulting in ITP-like syndrome, but are not the indicators of hypercoagulable state [5]. Markedly increased D-dimers and positive fibrin degradation products are the results of activated TF path supporting the diagnosis of combined micro-macrothrombosis [4]. The imaging study of venous combined micro-macrothrombotic syndrome may show as large, multiple, irregular, connected and extended, or disconnected macrothrombosis at the region of vascular injury and travelling afferently to the heart.

\subsection{Therapeutic Approach}

Since vaccine-induced venous endotheliopathy is triggered by the activation of the complement system, the best therapeutic approach would be anti-complement therapy that can suppress both inflammation and microthrombogenesis promoting ITP-like syndrome [4].

"Silent" ITP/ITP-like syndrome (i.e., vEA-VMTD) may be treated with an available antimicrothrombotic regimen of therapeutic plasma exchange or $\mathrm{N}$-acetyl cysteine to counteract venous microthrombogenesis or anticomplement therapy of intravenous immunoglobulins (IVIG) to stimulate the complement attenuation by amplifying C3 convertase level or act as a receptor for activated complement components [66,67]. Uncomplicated ITP-like syndrome should not be treated with platelet transfusion alone because it will increase platelet consumption and may even promote formation of complex forms of DVT when prolonged intravenous line is used for therapeutic plasma exchange, IVIG or platelet transfusion $[68,69]$.

Theoretically, the best approach for preventing CVST and VTE in the general population is not to vaccinate individuals with a condition or existing disease known to cause microvascular microthrombosis due to endotheliopathy, such as pregnancy, diabetes, uncontrolled hypertension, or autoimmune disease. If vaccinated, the individual should be 
alerted for the risk of "blood clots" and be instructed to avoid every circumstance of prolonged vascular access and any injury, such as head trauma, for a duration of 6 to 8 weeks. Clinical trials are needed for the treatment of venous combined micro-macrothrombosis utilizing antimicrothrombotic agent and anticoagulant.

Complement activation also plays a key role in vaccine-associated MOIS. If inflammatory syndrome(s), such as myocarditis, pericarditis, or Guillain-Barre syndrome, is overlapped with ITP-like syndrome, IVIG and steroid therapy would be appropriate to prevent endothelial dysfunction and support endothelial integrity [70].

\section{3. "Special Note" on TTP-Like Syndrome and ADAMTS13 after COVID-19 Vaccines}

In the pre-COVID-19 pandemic era, only a handful of cases of TTP-like syndrome had been recorded following vaccination [71]. Questionable cases of vaccine-associated TTPlike syndrome or relapsed TTP have been reported [72,73]. To the best of our knowledge well-documented case of de novo TTP after vaccination has not been documented after COVID-19 vaccines, but latest two cases of TTP-like syndrome after COVID-19 vaccine may support the relationship between COVID-19 vaccine and arterial endotheliopathy $[74,75]$. Since TTP-like syndrome (aEA-VMTD), which has often been associated with ADAMTS13 insufficiency and arterial endotheliopathy, it is possible that additional components of vaccines such as surfactants or adjuvants in vaccines might cause some effects on the arterial system via complement activation. In both aEA-VMTD and vEA-VMTD, ADAMTS13 insufficiency is a thrombophilic condition via the activated ULVWF path due to its heterozygous gene mutation/polymorphism or imbalanced/relative deficiency caused by excessive exocytosis of ULVWF multimers in endotheliopathy [5]. Therefore, in patient care and vaccine development, the medical community should be vigilant with the close monitoring of TTP-like syndrome and ITP-like syndrome and evaluate the role of ADAMTS13 for the diagnostic use and therapeutic potential [4-6].

\section{Conclusions}

The pathogenesis of vaccine-associated thrombocytopenia is characterized by venous endotheliopathy promoting microthrombosis and platelet consumption (ITP-like syndrome) triggered by an activated complement system due to inactivated pathogen/toxin/viral molecule and/or adjuvant conjugated with vaccine. When venous microthrombosis of vEAVMTD encounters fibrin meshes from an activated TF path following vaccine-unrelated vascular injury, VTE or CVST occurs as a result of the unifying mechanism of microthrombi and fibrin meshes, leading to venous combined micro-macrothrombosis. The clinical hemostatic disorders and inflammatory syndromes are consistent with attenuated sepsislike syndrome. Fortunately, arterial endotheliopathy has not been a major issue after COVID-19 vaccination.

Supplementary Materials: The following are available online at https://www.mdpi.com/article/ 10.3390/medicina57111163/s1, Table S1: Examples of organ inflammatory syndrome observed following vaccination (neither proven nor disproven in most of cases).

Author Contributions: Conceptualization, J.C.C. and H.B.H.; methodology, J.C.C.; formal analysis, J.C.C.; investigation, H.B.H.; resources, J.C.C.; data curation, J.C.C.; writing-original draft preparation, J.C.C.; writing - review and editing, H.B.H. All authors have read and agreed to the published version of the manuscript.

Funding: There is no support of funding in preparation and publication of this article.

Institutional Review Board Statement: Ethics approval and consent to participate: not applicable.

Data Availability Statement: Data sharing not applicable to this article as no datasets were generated or analyzed during the current study.

Acknowledgments: The authors express sincere appreciation to Emma Nichole Zebrowski for her drawing on the illustrative art works on the proposed pathogenetic mechanism of sepsis and vaccine as shown in Figures 1-3. 
Conflicts of Interest: Authors Jae C. Chang and H. Bradford Hawley have neither financial nor non-financial competing interests in regard to this article.

\section{References}

1. Franchini, M.; Liumbruno, G.M.; Pezzo, M. COVID-19 vaccine-associated immune thrombosis and thrombocytopenia (VITT): Diagnostic and therapeutic recommendations for a new syndrome. Eur. J. Haematol. 2021, 107, 173-180. [CrossRef] [PubMed]

2. Diaz, G.A.; Parsons, G.T.; Gering, S.K.; Meier, A.R.; Hutchinson, I.V.; Robicsek, A. Myocarditis and Pericarditis After Vaccination for COVID-19. JAMA 2021, e2113443.

3. Chang, J.C. Acute Respiratory Distress Syndrome as an Organ Phenotype of Vascular Microthrombotic Disease: Based on Hemostatic Theory and Endothelial Molecular Pathogenesis. Clin. Appl. Thromb. Hemost. 2019, 25, 1076029619887437. [CrossRef]

4. Chang, J.C. COVID-19 Sepsis: Pathogenesis and Endothelial Molecular Mechanisms Based on "Two-Path Unifying Theory" of Hemostasis and Endotheliopathy-Associated Vascular Microthrombotic Disease, and Proposed Therapeutic Approach with Antimicrothrombotic Therapy. Vasc. Health Risk Manag. 2021, 17, 273-298. [CrossRef]

5. Chang, J.C. Sepsis and septic shock: Endothelial molecular pathogenesis associated with vascular microthrombotic disease. Thromb. J. 2019, 17, 10. [CrossRef]

6. Chang, J.C. TTP-like syndrome: Novel concept and molecular pathogenesis of endotheliopathy-associated vascular microthrombotic disease. Thromb. J. 2018, 16, 20. [CrossRef]

7. Pulendran, B.; Ahmed, R. Immunological mechanisms of vaccination. Nat. Immunol. 2011, 12, 509-517. [CrossRef]

8. Huisman, W.; Martina, B.E.; Rimmelzwaan, G.F.; Gruters, R.A.; Osterhaus, A.D. Vaccine-induced enhancement of viral infections. Vaccine 2009, 27, 505-512. [CrossRef]

9. Hippisley-Cox, J.; Patone, M.; Mei, X.W.; Saatci, D.; Dixon, S.; Khunti, K.; Zaccardi, F.; Watkinson, P.; Shankar-Hari, M.; Doidge, J.; et al. Risk of thrombocytopenia and thromboembolism after covid-19 vaccination and SARS-CoV-2 positive testing: Self-controlled case series study. BMJ 2021, 374, n1931. [CrossRef]

10. Kuter, D.J. Exacerbation of immune thrombocytopenia following COVID-19 vaccination. Br. J. Haematol. 2021. [CrossRef]

11. Abdalkader, M.; Shaikh, S.P.; Siegler, J.E.; Cervantes-Arslanian, A.M.; Tiu, C.; Radu, R.A.; Tiu, V.E.; Jillella, D.V.; Mansour, O.Y.; Vera, V.; et al. Cerebral Venous Sinus Thrombosis in COVID-19 Patients: A Multicenter Study and Review of Literature. J. Stroke Cerebrovasc. Dis. 2021, 30, 105733. [CrossRef]

12. Pishko, A.M.; Bussel, J.B.; Cines, D.B. COVID-19 vaccination and immune thrombocytopenia. Nat. Med. 2021, 27, 1145-1146. [CrossRef] [PubMed]

13. Saudagar, V.; Patil, S.; Goh, S.; Pothiawala, S. Vigilance regarding immune thrombocytopenic purpura after COVID-19 vaccine. Ir. J. Med. Sci. 2021, 1-2.

14. Sharifian-Dorche, M.; Bahmanyar, M.; Sharifian-Dorche, A.; Mohammadi, P.; Nomovi, M.; Mowla, A. Vaccine-induced immune thrombotic thrombocytopenia and cerebral venous sinus thrombosis post COVID-19 vaccination: A systematic review. J. Neurol. Sci. 2021, 428, 117607. [CrossRef] [PubMed]

15. Rizk, J.G.; Gupta, A.; Sardar, P.; Henry, B.M.; Lewin, J.C.; Lippi, G.; Lavie, C.J. Clinical Characteristics and Pharmacological Management of COVID-19 Vaccine-Induced Immune Thrombotic Thrombocytopenia With Cerebral Venous Sinus Thrombosis: A Review. JAMA Cardiol. 2021. [CrossRef]

16. Verma, A.K.; Lavine, K.J.; Lin, C.Y. Myocarditis after Covid-19 mRNA Vaccination. N. Engl. J. Med. 2021. [CrossRef]

17. The Chief Medical Office of Health Alberta. Myocarditis and/or Pericarditis following COVID-19 Vaccines. Available online: https:/ / www.alberta.ca/assets/documents/health-myocarditis-and-pericarditis-following-covid.pdf (accessed on 22 July 2021).

18. Chang, J.C. Thrombocytopenia in critically ill patients due to vascular microthrombotic disease: Pathogenesis based on "twoactivation theory of the endothelium". Vascul. Dis. Ther. 2017, 2, 1-7. [CrossRef]

19. Zufferey, A.; Kapur, R.; Semple, J.W. Pathogenesis and Therapeutic Mechanisms in Immune Immune Thrombocytopenia (ITP). J. Clin. Med. 2017, 6, 16. [CrossRef]

20. Audia, S.; Mahévas, M.; Samson, M.; Godeau, B.; Bonnotte, B. Pathogenesis of immune thrombocytopenia. Autoimmun. Rev. 2017, 16, 620-632. [CrossRef]

21. LeVine, D.N.; Brooks, M.B. Immune thrombocytopenia (ITP): Pathophysiology update and diagnostic dilemmas. Vet. Clin. Pathol. 2019, 48 (Suppl. 1), 17-28. [CrossRef] [PubMed]

22. Johnsen, J. Pathogenesis in immune thrombocytopenia: New insights. Hematol. Am. Soc. Hematol. Educ. Program 2012, 2012, 306-312. [CrossRef]

23. McGonagle, D.; De Marco, G.; Bridgewood, C. Mechanisms of Immunothrombosis in Vaccine-Induced Thrombotic Thrombocytopenia (VITT) Compared to Natural SARS-CoV-2 Infection. J. Autoimmun. 2021, 121, 102662. [CrossRef] [PubMed]

24. Favaloro, E.J. Laboratory testing for suspected COVID-19 vaccine-induced (immune) thrombotic thrombocytopenia. Int. J. Lab. Hematol. 2021, 43, 559-570. [CrossRef] [PubMed]

25. Scully, M.; Singh, D.; Lown, R.; Poles, A.; Solomon, T.; Levi, M.; Goldblatt, D.; Kotoucek, P.; Thomas, W.; Lester, W. Pathologic Antibodies to Platelet Factor 4 after ChAdOx1 nCoV-19 Vaccination. N. Engl. J. Med. 2021, 384, 2202-2211. [CrossRef] [PubMed]

26. Greinacher, A.; Thiele, T.; Warkentin, T.E.; Weisser, K.; Kyrle, P.A.; Eichinger, S. Thrombotic Thrombocytopenia after ChAdOx1 nCov-19 Vaccination. N. Engl. J. Med. 2021, 384, 2092-2101. [CrossRef] 
27. Terpos, E.; Politou, M.; Ntanasis-Stathopoulos, I.; Karalis, V.; Merkouri, E.; Fotiou, D.; Gavriatopoulou, M.; Malandrakis, P.; Kastritis, E.; Trougakos, I.P.; et al. High Prevalence of Anti-PF4 Antibodies Following ChAdOx1 nCov-19 (AZD1222) Vaccination Even in the Absence of Thrombotic Events. Vaccines 2021, 9, 712. [CrossRef]

28. Chang, J.C. Hemostasis based on a novel 'two-path unifying theory' and classification of hemostatic disorders. Blood Coagul. Fibrinolysis. 2018, 29, 573-584. [CrossRef] [PubMed]

29. İremli, B.G.; Şendur, S.N.; Ünlütürk, U. Three Cases of Subacute Thyroiditis Following SARS-CoV-2 Vaccine: Post-vaccination ASIA Syndrome. J. Clin. Endocrinol. Metab. 2021, 106, 2066-2605. [CrossRef]

30. Domiguez, M.P.; Medina, G.; Sánchez Valadez, T.I.; Jara, L.J. Two Cases of Graves' Disease Following SARS-CoV-2 Vaccination: An Autoimmune/Inflammatory Syndrome Induced by Adjuvants. Thyroid 2021, 31.

31. Keshavarz, P.; Yazdanpanah, F.; Rafiee, F.; Mizandari, M. Lymphadenopathy Following COVID-19 Vaccination: Imaging Findings Review. Acad. Radiol. 2021, 28, 1058-1071. [CrossRef]

32. Hiller, N.; Goldberg, S.N.; Cohen-Cymberknoh, M.; Vainstein, V.; Simanovsky, N. Lymphadenopathy Associated with the COVID-19 Vaccine. Cureus 2021, 13, e13524.

33. Talotta, R.; Robertson, E.S. Antiphospholipid antibodies and risk of post-COVID-19 vaccination thrombophilia: The straw that breaks the camel's back? Cytokine Growth Factor Rev. 2021, 60, 52-60. [CrossRef] [PubMed]

34. Uzun, G.; Althaus, K.; Bakchoul, T. No Correlation between Anti-PF4 and Anti-SARS-CoV-2 Antibodies after ChAdOx1 nCoV-19 Vaccination. N. Engl. J. Med. 2021, 385, 1334-1336. [CrossRef]

35. Castillo-Martínez, D.; Torres, Z.; Amezcua-Guerra, L.M.; Pineda, C. Are antiphospholipid antibodies just a common epiphenomenon or are they causative of immune-mediated coagulopathy in COVID-19? Clin. Rheumatol. 2021, 40, 3015-3019. [CrossRef] [PubMed]

36. Severinsen, M.T.; Engebjerg, M.C.; Farkas, D.K.; Jensen, A.Ø.; Nørgaard, M.; Zhao, S.; Sørensen, H.T. Risk of venous thromboembolism in patients with primary chronic immune thrombocytopenia: A Danish population-based cohort study. Br. J. Haematol. 2011, 152, 360-362. [CrossRef] [PubMed]

37. Rodeghiero, F. ITP and thrombosis: An intriguing association. Blood Adv. 2017, 1, 2280. [CrossRef]

38. Moulis, G.; Audemard-Verger, A.; Arnaud, L.; Luxembourger, C.; Montastruc, F.; Gaman, A.M.; Svenungsson, E.; Ruggeri, M.; Mahevas, M.; Gerfaud-Valentin, M.; et al. Risk of thrombosis in patients with primary immune thrombocytopenia and antiphospholipid antibodies: A systematic review and meta-analysis. Autoimmun. Rev. 2016, 15, 203-209. [CrossRef]

39. Chang, J.C. Thrombogenesis and thrombotic disorders based on 'two-path unifying theory of hemostasis': Philosophical, physiological, and phenotypical interpretation. Blood Coagul Fibrinolysis 2018, 29, 585-595. [CrossRef] [PubMed]

40. Chang, J.C. Stroke Classification: Critical Role of Unusually Large von Willebrand Factor Multimers and Tissue Factor on Clinical Phenotypes Based on Novel "Two-Path Unifying Theory" of Hemostasis. Clin. Appl. Thromb. Hemost. 2020, 26, 1076029620913634. [CrossRef]

41. Chang, J.C. Disseminated intravascular coagulation: New identity as endotheliopathy-associated vascular microthrombotic disease based on in vivo hemostasis and endothelial molecular pathogenesis. Thromb. J. 2020, 18, 25. [CrossRef]

42. Giladi, O.; Steinberg, D.M.; Peleg, K.; Tanne, D.; Givon, A.; Grossman, E.; Klein, Y.; Avigdori, S.; Greenberg, G.; Katz, R.; et al. Head trauma is the major risk factor for cerebral sinus-vein thrombosis. Thromb. Res. 2016, 137, 26-29. [CrossRef]

43. Salih, F.; Schönborn, L.; Kohler, S.; Franke, C.; Möckel, M.; Dörner, T.; Bauknecht, H.C.; Pille, C.; Graw, J.A.; Alonso, A.; et al. Vaccine-Induced Thrombocytopenia with Severe Headache. N. Engl. J. Med. 2021. [CrossRef] [PubMed]

44. Shahsavarzadeh, T.; Javanmard, S.H.; Saadatnia, M. Impact of factor VIII and von Willebrand factor plasma levels on cerebral venous and sinus thrombosis: Are they independent risk factors? Eur. Neurol. 2011, 66, 243-246. [CrossRef]

45. Bugnicourt, J.M.; Roussel, B.; Tramier, B.; Lamy, C.; Godefroy, O. Cerebral venous thrombosis and plasma concentrations of factor VIII and von Willebrand factor: A case control study. J. Neurol. Neurosurg. Psychiatry 2007, 78, 699-701. [CrossRef] [PubMed]

46. Burns, A.; Wilson, E.; Harber, M.; Brunton, C.; Sweny, P. Cerebral venous sinus thrombosis in minimal change nephrotic syndrome. Nephrol. Dial. Transplant. 1995, 10, 30-34. [CrossRef]

47. Bolayır, A.; Çiğdem, B. The relationship between ABO blood types and development of cerebral venous sinus thrombosis. Cum. Med. J. 2017, 39, 602-607. [CrossRef]

48. Rawala, M.S.; Noorani, M.M.; Gulati, R.; Waqas, S.; Dave, D. Elevated Factor VIII Level Associated with Transverse Cerebral Venous Sinus Thrombosis. Am. J. Case Rep. 2019, 20, 274-277. [CrossRef]

49. De Michele, M.; Iacobucci, M.; Chistolini, A.; Nicolini, E.; Pulcinelli, F.; Cerbelli, B.; Merenda, E.; Schiavo, O.G.; Sbardella, E.; Berto, I.; et al. Malignant cerebral infarction after ChAdOx1 nCov-19 vaccination: A catastrophic variant of vaccine-induced immune thrombotic thrombocytopenia. Nat. Commun. 2021, 12, 4663. [CrossRef]

50. Anadure, R.K.; Nagaraja, D.; Christopher, R. Plasma factor VIII in non-puerperal cerebral venous thrombosis: A prospective case-control study. J. Neurol. Sci. 2014, 339, 140-143. [CrossRef] [PubMed]

51. Vecht, L.; Zuurbier, S.M.; Meijers, J.C.M.; Coutinho, J.M. Elevated factor VIII increases the risk of cerebral venous thrombosis: A case-control study. J. Neurol. 2018, 265, 1612-1617. [CrossRef]

52. Yokota, H.; Ida, Y.; Sugiura, S.; Sasaki, K.; Itoh, H. Cerebral venous sinus thrombosis with increased factor VIII activity in an adult with iron deficiency anemia. Neurol. India 2014, 62, 674-675. [CrossRef]

53. Thachil, J. Lessons learnt from COVID-19 coagulopathy. EJHaem 2021. [CrossRef] [PubMed] 
54. Afshari, F.T.; Yakoub, K.M.; Zisakis, A.; Thomas, A.; Ughratdar, I.; Sturman, S.; Belli, A. Traumatic dural venous sinus thrombosis; a challenge in management of head injury patients. J. Clin. Neurosci. 2018, 57, 169-173. [CrossRef]

55. Mastellos, D.C.; Skendros, P.; Lambris, J.D. Is complement the culprit behind COVID-19 vaccine-related adverse reactions? J. Clin. Investig. 2021, 131, e151092. [CrossRef]

56. Behet, M.C.; Kurtovic, L.; van Gemert, G.J.; Haukes, C.M.; Siebelink-Stoter, R.; Graumans, W.; van de Vegte-Bolmer, M.G.; Scholzen, A.; Langereis, J.D.; Diavatopoulos, D.A.; et al. The Complement System Contributes to Functional Antibody-Mediated Responses Induced by Immunization with Plasmodium falciparum Malaria Sporozoites. Infect. Immun. 2018, 86, e00920-17. [CrossRef]

57. Lind, L.; Hulthe, J.; Johansson, A.; Hedner, E. Endotoxin-induced and vaccine-induced systemic inflammation both impair endothelium-dependent vasodilation, but not pulse wave reflection. Vasc. Health Risk Manag. 2012, 8, 447-453. [CrossRef] [PubMed]

58. Clapp, B.R.; Hingorani, A.D.; Kharbanda, R.K.; Mohamed-Ali, V.; Stephens, J.W.; Vallance, P.; MacAllister, R.J. Inflammationinduced endothelial dysfunction involves reduced nitric oxide bioavailability and increased oxidant stress. Cardiovasc. Res. 2004, 64, 172-178. [CrossRef] [PubMed]

59. Yu, J.; Yuan, X.; Chen, H.; Chaturvedi, S.; Braunstein, E.M.; Brodsky, R.A. Direct activation of the alternative complement pathway by SARS-CoV-2 spike proteins is blocked by factor D inhibition. Blood 2020, 136, 2080-2089. [CrossRef]

60. Hattori, R.; Hamilton, K.K.; McEver, R.P.; Sims, P.J. Complement proteins C5b-9 induce secretion of high molecular weight multimers of endothelial von Willebrand factor and translocation of granule membrane protein GMP-140 to the cell surface. J. Biol. Chem. 1989, 264, 9053-9060. [CrossRef]

61. Hamad, I.; Hunter, A.C.; Szebeni, J.; Moghimi, S.M. Poly(ethylene glycol)s generate complement activation products in human serum through increased alternative pathway turnover and a MASP-2-dependent process. Mol. Immunol. 2008, 46, 225-232. [CrossRef]

62. Pannuzzo, M.; Esposito, S.; Wu, L.P.; Key, J.; Aryal, S.; Celia, C.; Di Marzio, L.; Moghimi, S.M.; Decuzzi, P. Overcoming Nanoparticle-Mediated Complement Activation by Surface PEG Pairing. Nano Lett. 2020, 20, 4312-4321. [CrossRef] [PubMed]

63. Wibroe, P.P.; Petersen, S.V.; Bovet, N.; Laursen, B.W.; Moghimi, S.M. Soluble and immobilized graphene oxide activates complement system differently dependent on surface oxidation state. Biomaterials 2016, 78, 20-26. [CrossRef]

64. Szebeni, J.; Muggia, F.; Gabizon, A.; Barenholz, Y. Activation of complement by therapeutic liposomes and other lipid excipientbased therapeutic products: Prediction and prevention. Adv. Drug Deliv. Rev. 2011, 63, 1020-1030. [CrossRef]

65. Lin, J.J.; Hsiao, H.J.; Chan, O.W.; Wang, Y.; Hsia, S.H.; Chiu, C.H. Increased serum thrombomodulin level is associated with disease severity and mortality in pediatric sepsis. PLOS ONE 2017, 12, e0182324. [CrossRef]

66. Lutz, H.U.; Stammler, P.; Bianchi, V.; Trüeb, R.M.; Hunziker, T.; Burger, R.; Jelezarova, E.; Späth, P.J. Intravenously applied IgG stimulates complement attenuation in a complement-dependent autoimmune disease at the amplifying $\mathrm{C} 3$ convertase level. Blood 2004, 103, 465-472. [CrossRef] [PubMed]

67. Frank, M.M.; Basta, M.; Fries, L.F. The effects of intravenous immune globulin on complement-dependent immune damage of cells and tissues. Clin. Immunol. Immunopathol. 1992, 62 Pt 2, S82-S86. [CrossRef]

68. McCrae, K. Immune Thrombocytopenia with Pulmonary Embolism and Deep-Vein Thrombosis: Recommendations for Bone Marrow Aspirate and Biopsy. Hematologist 2011, 8, 6. [CrossRef]

69. Sarpatwari, A.; Bennett, D.; Logie, J.W.; Shukla, A.; Beach, K.J.; Newland, A.C.; Sanderson, S.; Provan, D. Thromboembolic events among adult patients with primary immune thrombocytopenia in the United Kingdom General Practice Research Database. Haematologica 2010, 95, 1167-1175. [CrossRef]

70. Bozkurt, B.; Kamat, I.; Hotez, P.J. Myocarditis With COVID-19 mRNA Vaccines. Circulation 2021, 144, 471-484. [CrossRef]

71. Yavaşoğlu, İ. Vaccination and Thrombotic Thrombocytopenic Purpura. Turk. J. Haematol. 2020, 37, 218-219. [CrossRef] [PubMed]

72. Ruhe, J.; Schnetzke, U.; Kentouche, K.; Prims, F.; Baier, M.; Herfurth, K.; Schlosser, M.; Busch, M.; Hochhaus, A.; Wolf, G. Acquired thrombotic thrombocytopenic purpura after first vaccination dose of BNT162b2 mRNA COVID-19 vaccine. Ann. Hematol. 2021, $1-3$.

73. Sissa, C.; Al-Khaffaf, A.; Frattini, F.; Gaiardoni, R.; Mimiola, E.; Montorsi, P.; Melara, B.; Amato, M.; Peyvandi, F.; Franchini, M. Relapse of thrombotic thrombocytopenic purpura after COVID-19 vaccine. Transfus. Apher. Sci. 2021. [CrossRef] [PubMed]

74. Waqar, S.H.B.; Khan, A.A.; WMemon, S. Thrombotic thrombocytopenic purpura: A new menace after COVID bnt162b2 vaccine. Int. J. Hematol. 2021, 114, 626-629. [CrossRef] [PubMed]

75. Lee, H.P.; Selvaratnam, V.; Rajasuriar, J.S. Thrombotic thrombocytopenic purpura after ChAdOx1 nCoV-19 vaccine. BMJ Case Rep. 2021, 14, e246049. [CrossRef] [PubMed] 